11. Puffer JC. The American Board of Family Medicine certification examination: a proxy for quality. Fam Med. 2011;43(6):433-434.

12. O'Neill TR, Puffer JC. Maintenance of certification and its association with the clinical knowledge of family physicians. Acad Med. 2013;88(6):780-787.

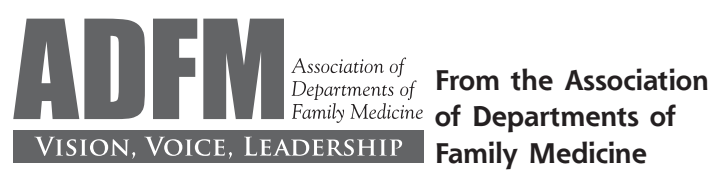

Ann Fam Med 2014;282-283. doi: 10.1370/afm.1648.

\section{WHAT DOES TEAM LEADERSHIP MEAN IN THE PCMH?}

A decade ago, the Future of Family Medicine report supported the development of a new model of practice. ${ }^{1}$ This model quickly evolved into a clinical care entity known as the Patient-centered Medical Home $(\mathrm{PCMH})$. There was much synergy for the new PCMH model between the primary care community and the business community. Paul Grundy, IBM Corporation's Global Director of Healthcare Transformation, in concert with 4 practicing physician organizations, led a movement to identify the PCMH model as the cornerstone of a new organization, the Patient-Centered Primary Care Collaborative (PCPCC). A critical step to catalyzing the PCPCC in 2007-2008 was defining the Joint Principles of the Patient Centered Medical Home adopted by the 4 professional societies who came together to form the PCPCC (the American Academy of Family Physicians (AAFP), the American Academy of Pediatrics, the American College of Physicians, and the American Osteopathic Association). These joint principles were then endorsed by more organizations in family medicine including the Association of Departments of Family Medicine (ADFM).

Since its release, one of the principles in the original language of the joint principles of the medical home has been a source of controversy causing ADFM leadership to evolve in our thinking ${ }^{2}$ :

"Physician-directed medical practice-the personal physician leads a team of individuals at the practice level who collectively take responsibility for the ongoing care of patients."

It is also noteworthy that the landscape of the "physician's practice" has changed with far fewer physicianowned solo practices today than were in existence a decade ago.

In early 2014, ADFM, along with our sister academic family medicine organizations in the Council of
Academic Family Medicine (CAFM): the Association of Family Medicine Residency Directors (AFMRD), the North American Primary Care Research Group (NAPCRG), and the Society of Teachers of Family Medicine (STFM), published "The Four Pillars of Primary Care Physician Workforce Reform: A Blueprint for Future Activity." ${ }^{\prime 3}$ The AAFP and ABFM collaborated with CAFM to approve the "four pillars" concept featured in this publication. A notable bullet in the four pillars model under practice transformation states:

"Practice teams must include generalist physician leaders who serve as role models, and who deliver comprehensive, broad-scope primary care."

The language contained within this bullet was very intentional to mean that generalist physician leaders were to be on teams among other bealth professional leaders. Leadership within teams is 1 of the 4 core skills to great team functioning and should not imply a hierarchical structure. ${ }^{4}$ In fact, these same teams should also include other leaders such as nurses, nurse practitioners, social workers, pharmacists, and psychologists, to name a few. With effective teams, leadership skills should be practiced by all members of the team-along with the other core skills of mutual support, clear communication, and situation monitoring in the work environment. ${ }^{5}$ Our interpretation behind the intent of the four pillars language is in alignment with the sentiments expressed recently by Dr. Denise Rodgers, MD, FAAFP, Vice Chancellor for Interprofessional Programs and Director of the Rutgers Urban Health and Wellness Institute, Rutgers Biomedical and Health Sciences. In her plenary address, "Partners in Training: Interprofessional Education," at the 2014 ADFM Winter meeting, Dr. Rodgers commented that in a given clinical care situation, the physician may be more remotely connected to a team led by another health professional. There are times when the physician will be at the front of the team. There are other times when the physician will step back and not be the central driver of the team's activity, but ready to enter into the clinical care decision making when, and if, needed and willing to play a supportive role.

Leadership is often interpreted to mean a position of being "at the helm" in command at all times. True leadership happens at many levels and is often enacted more remotely. How we define and interpret the meaning of leadership on clinical care teams in the PCMH is a critical conversation to have among health professionals as we move together to achieve the Triple Aim ${ }^{6}$ for the American public.

This commentary has been prepared by members of the ADFM Executive Committee who were serving on the Council of Academic Family Medicine (CAFM) at the time "The Four Pillars for Primary Care Physi- 
cian Workforce Reform: A Blueprint for Future Activity" was written.

Paul James, $M D_{i}$ Ardis Davis, MSW and Barbara Thompson, MD

\section{References}

1. Martin JC, Avant RF, Bowman MA, et al; Future of Family Medicine Project Leadership Committee. The future of family medicine: a collaborative project of the family medicine community. Ann Fam Med. 2004;2(Suppl 1):S3-S32.

2. Patient-Centered Primary Care Collaborative. Joint principles of the patient-centered medical home. http://www.pcpcc.org/about/ medical-home.

3. The Four Pillars for Primary Care Physician Workforce Reform. The four pillars for primary care physician workforce reform: a blueprint for future activity. Ann Fam Med. 2014;12(1):83-87.

4. Clancy CM, Tornberg DN. TeamSTEPPS: assuring optimal teamwork in clinical settings. Am J Med Qual. 2007;22(3):214-217.

5. TeamSTEPPS Primary Care Version. http://www.ahrq.gov/professionals/education/curriculum-tools/teamstepps/primarycare/slpcobt.html.

6. Berwick DM, Nolan TW, Whittington J. The triple aim: care, health, and cost. Health Aff (Millwood). 2008;27(3):759-769.

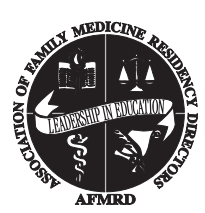

From the Association of Family Medicine Residency Directors

Ann Fam Med 2014;283. doi: 10.1370/afm.1649.

\section{THE ALLOPATHIC AND OSTEOPATHIC WORLDS: ALIGNING OUR TRAINING TO MEET OUR PATIENTS' NEEDS}

Over the past year, many of us learned about the discussions between the Accreditation Council for Graduate Medical Education (ACGME) and the American Osteopathic Association (AOA) regarding the development of joint accreditation standards. This represented a major rapprochement between two physician accreditation bodies that have been separated ideologically for decades. Many of us were discouraged, however, when these discussions apparently stalled. Further concern arose in response to a recent proposal by the AOA to create a new competency-based educational model that calls for an integration of medical school and graduate medical education, thereby shortening the training process. This could have resulted in primary care physicians being trained in as few as five years. The AOA described this as a change to address many of the concerns voiced by the ACGME, including the physician workforce shortage, increased need for primary care, and medical student debt burden.

As we entered 2014, there was a looming feeling of division between the AOA and the ACGME. So what a welcome surprise on February 26, 2014, when email inboxes around the country were buzzing with excitement about announcements from both the ACGME and AOA that they had reached a historic agreement to create a single graduate medical education accreditation system.

As program directors, we will be navigating many transitions and will be facing many implementation challenges ahead. We must remember that these challenges are necessary to assure consistent high quality educational programs. Considering that the fate of GME funding continues to be uncertain, yet the need for physicians continues to grow, the graduate medical education community must treat training programs and all residency positions as "national resources," as Dr. Nasca suggested during his CEO address at the 2014 ACGME Annual Education Conference. A single accreditation system will help us to be more united in our role as fierce advocates and stewards of residency training.

This action could not come at a more opportune moment in family medicine. As the country struggles with solutions to the crisis in health care, our specialty is working hard to clearly define the role and value of family medicine, through efforts such as the Future of Family Medicine 2.0 project. The specific solutions and definitions may not be crystalized at this time, however, the absolute requirement of unity is clear. We need to unite and speak with one clear voice as decisions and policies are made locally, regionally, and nationally.

As program directors, we have long recognized that quality physicians come from both pathways. Our increased application numbers are in part due to the greater numbers of osteopathic students as new schools are created and current schools increase their class sizes. Osteopathic schools have a solid tradition of graduating higher percentages of primary care physicians than do the allopathic schools. A single accreditation system can help free us of the politics that distracted us from our daily reality of training a quality primary care workforce.

We look forward to embarking on this historic journey. Many program directors and students are anxiously anticipating the decision regarding the future of the AOA and National Residency Matching Program matches and can only hope for their timely unification as well. The news of a single accreditation system is a positive step toward training a workforce that provides comprehensive, cost effective, and patient-centered care for modern times.

Lisa Maxwell, MD and Michael Tuggy, MD Natasha Bbuyan, $M D_{i}$ Brian Crownover, $M D_{\text {; }}$ Grant Hoekzema, MD, Michael Mazzone, $M D_{\text {; }}$

W. Fred Miser, $M D_{i}$ Karen Mitchell, $M D_{\text {; }}$ Stephen Schultz, MDi, Todd Shaffer, MD, MBA 